\title{
High origin of the third digital branch of the median nerve
}

\author{
Konstantinos Natsis \\ Laboratory of Anatomy, School of Medicine, Faculty of Health Sciences, Aristotle University of Thessaloniki, Thessaloniki, Macedonia, Greece
}

\begin{abstract}
During a routine cadaveric dissection, we came across an anatomical variation at the level of the right forearm of a 77-year-old Caucasian male cadaver. Proximal to the superior border of the flexor retinaculum, we observed the median nerve giving a separate branch. It was the third common palmar digital nerve running distally from the ulnar side of the median nerve and coursing through the flexor digitorum superficialis muscle. In the distal part of the palm, it was divided into two proper palmar digital nerves for the adjacent sides of middle and ring fingers.
\end{abstract}

Keywords: carpal tunnel; entrapment neuropathy; median nerve variations; third common digital nerve

Anatomy 2016;10(1):71-74 @2016 Turkish Society of Anatomy and Clinical Anatomy (TSACA)

\section{Introduction}

Distal to the transverse carpal ligament, the median nerve flattens and divides into the lateral and medial branches. The lateral branch gives the first common palmar digital nerve and one proper palmar digital nerve to supply the thumb and radial side of the index finger. The medial branch divides into two common palmar digital nerves, second and third, to supply the adjacent sides of the index, middle, and ring fingers. They also supply the first and second lumbrical muscles with separate twigs. Usually, the digital nerves pass distally deep to the superficial palmar arch and its digital vessels.

The high division of the median nerve is an anatomical variation reported in the literature with an incidence of $3 \% .^{[1-3]}$ This variation is often combined with the presence of the median artery. ${ }^{[2,47]}$ However, high division of the median nerve does not always co-exist with the median artery. A transmuscular course of a median nerve branch in the forearm has also been described in the literature and it has been associated with entrapment neuropathy with symptoms resembling carpal tunnel syndrome. ${ }^{[8]}$ In the present study, we present a similar case of high division of the median nerve accompanied by a transmuscular course of one branch.

\section{Case Report}

During a routine dissection of the right upper limb of a 77year-old Greek male cadaver, we came across an anatomical variation of the median nerve in the forearm (Figure 1). There were no signs of trauma or previous surgery in the right upper limb. After the elevation of palmaris longus at the level of its musculotendinous junction, $7.3 \mathrm{~cm}$ proximal to the upper border of the flexor retinaculum, we observed the median nerve giving rise to a separate branch. It was the third common palmar digital nerve which ran distally from the medial side of median nerve coursing through the flexor digitorum superficialis muscle. The nerve passed under the flexor retinaculum in the carpal tunnel, located between the flexor digitorum superficialis muscle and the ulnar artery. In the distal part of the palm, it pursued a course deep to the superficial palmar arch and divided into two proper palmar digital nerves for the adjacent sides of middle and ring fingers. The corresponding two digital arteries were located deep to both of the proper palmar digital nerves. This unusual branch of the median nerve also supplied the third lumbrical muscle, just before its division into the proper palmar digital nerves.

\section{Discussion}

According to the literature, the median nerve may be associated with several variations, such as unusual communica- 


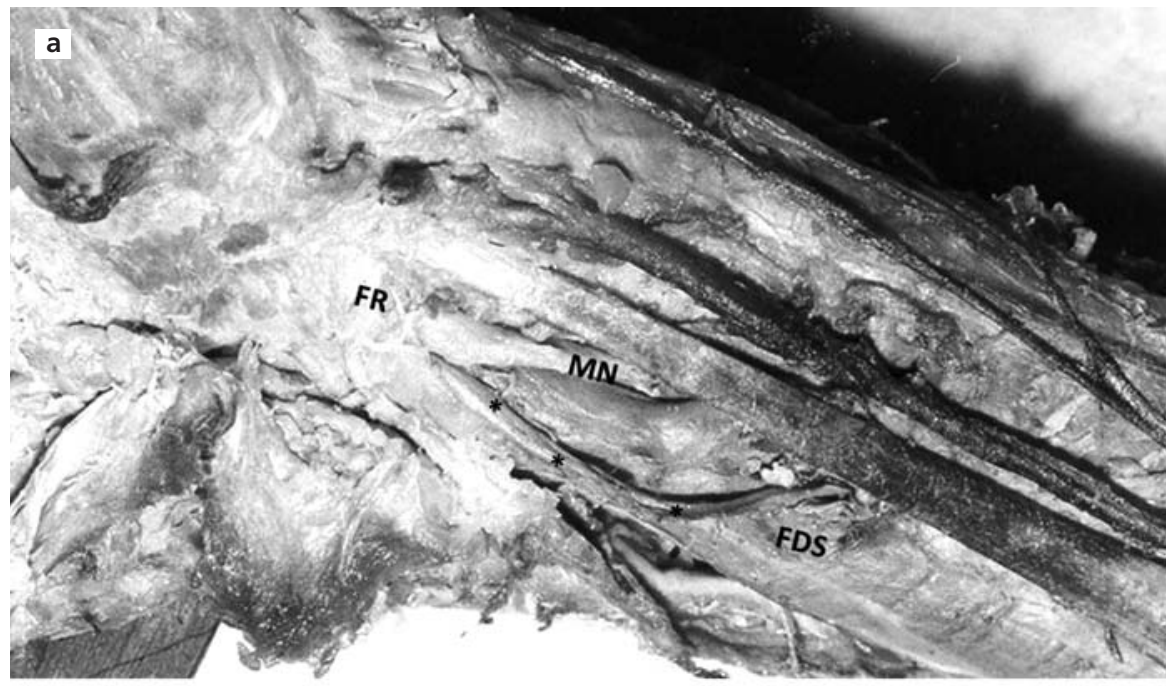

Figure 1. (a, b). Two levels of dissection. The median nerve $(\mathrm{MN})$ at the right forearm was giving an atypical ramus (*). That ramus was the third common palmar digital nerve and ran distally through the flexor digitorum superficialis muscle (FDS), under the flexor retinaculum (FR) medial to the $\mathrm{MN}$, and in the palm deep to the superficial palmar arch (A). The nerve was divided into two proper palmar digital nerves for the adjacent sides of middle and ring fingers.

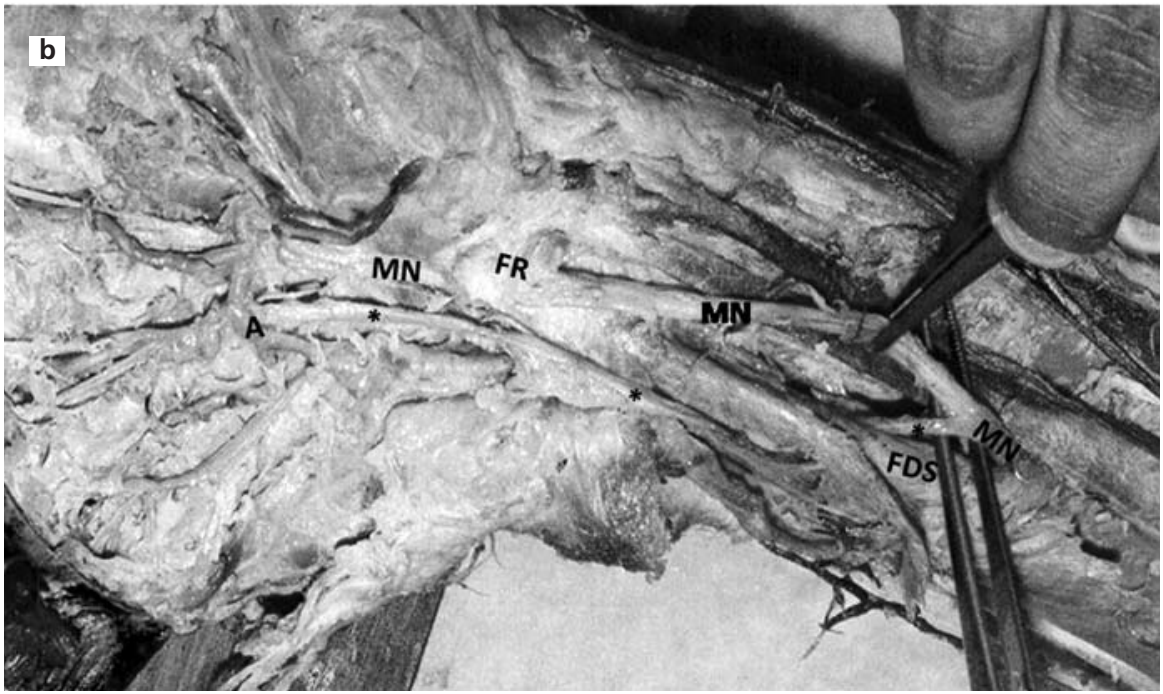

tions with other nerves, ${ }^{[0]}$ splitting of the median nerve ${ }^{[9,10]}$ and atypical muscle innervation. ${ }^{[1]]}$ The high division of the median nerve is an anatomical variation which has been reported in the literature with an incidence of $3 \% .^{[1-3]}$

Lanz ${ }^{[5]}$ classified variations of the median nerve into four groups: 1) division into a thenar branch; 2) accessory branches of the median nerve in the distal portion of the carpal tunnel; 3) a far proximal division in the nerve track occurring at the level of the forearm; 4) accessory branches that leave the nerve trunk proximal to the carpal tunnel. Lanz reported the incidence of the high division of the median nerve as $2.8 \% .^{[5]}$ This entity may often be associated with other anatomical variations as well. ${ }^{[5,9,12-15]}$ Usually, it is accompanied by the presence of a persistent median artery. Knowledge of this fact could help orthopedic surgeons to avoid damage of the coexisting persistent median artery. In our case, there was no persistent median artery or any other concomitant variation.

Sundaram et al. ${ }^{[9]}$ described a variation of the median nerve in which the nerve split $5 \mathrm{~cm}$ proximal to the flexor retinaculum. The split portion of the median nerve continued distally as the third common palmar digital nerve, which passed anterior to the long flexor tendons, and just proximal to the space between middle and ring finger it was divided into two proper palmar digital nerves. Barbe et al. ${ }^{[1]}$ found a unilateral variation of the median nerve in 27 out of 75 hands (36\%), and a bilateral variation in only one hand. These variations included either subligamentous or transligamentous branching of the thenar branch (Lanz Type I; 33\%), as well as a high division of the median nerve in two hands (Lanz Type III; $2.6 \%)$. 
Another relative classification system was reported by Engineer et al. ${ }^{[16]}$ who identified three types of origin of the third common digital nerve: type I originating proximal to the distal edge of the transverse carpal ligament (15\%); type II originating distal to the transverse carpal ligament but proximal to the superficial palmar arch (70\%); and type III originating distal to the transverse carpal ligament and at or distal to the superficial palmar arch (15\%). The median nerve variation in our case fits better to Lanz type III, while Engineer et al.'s classification does not include the variation in our case. ${ }^{[16]}$

Agarwal et al. ${ }^{[17]}$ presented a relatively high incidence of median nerve variations (50\% of 52 cadaveric hands) with high division of the median nerve (into medial and lateral branches and early branching of the second common digital nerve) in $11.53 \%$.

The course of the third common digital nerve through the flexor digitorum superficialis muscle, as we noticed, could lead to entrapment neuropathy with symptoms resembling carpal tunnel syndrome. Indeed, FernandezGarcia et al.$^{[8]}$ presented a case of a high division of median nerve which had one branch passing through the flexor digitorum superficialis tendon of middle finger causing nerve compression during muscle contraction and resulting in pain and dysesthesia of the middle finger, falsely mimicking carpal tunnel syndrome symptomatology.

Palmer and Toivonen ${ }^{[18]}$ mentioned that the common digital nerve of the third web space was the most frequently injured nerve branch during carpal tunnel release, regardless of the surgical method (open or endoscopic). When a high division of the median nerve is encountered during surgical release, both branches should be decompressed. ${ }^{[19]}$ Moreover, in some cases a split median nerve has forced surgeons to switch to open release from endoscopic surgery. ${ }^{[20]}$

A high division of the median nerve may predispose to compression in the carpal tunnel because of its relatively higher cross sectional area compared to a single median nerve. ${ }^{[5]}$ Two other studies ${ }^{[2,22]}$ demonstrated a high division of the median nerve in the carpal tunnel in $36(19 \%)$ of 194 wrists and 32 (19\%) of 170 patients. There were also cases with bilateral median nerve variations causing a bilateral carpal tunnel syndrome. ${ }^{[23]}$ However, patient data derived from a recent combined clinical, electrophysiological and ultrasonographical approach highlight that bifid median nerve is not an independent risk factor for carpal tunnel syndrome development. ${ }^{[2]]}$ In clinical cases that present a variation similar to our case, great care should be taken in decompression of the carpal tunnel, since the third common digital nerve will be present as an individual structure within the tunnel.
In conclusion, the surgical procedure is not complicated per se, but the variations of the median nerve, which make it risky. In cases with variations similar to the one reported above, carpal tunnel release might not lead to complete relief symptoms. On the other hand, there is an increased risk of iatrogenic injury to the supernumerary nerve branch that courses through the carpal tunnel.

\section{References}

1. Kessler I. Unusual distribution of the median nerveat the wrist. Clin Orthop Rel Res 1969;67:124-6.

2. Eiken O, Cartsman N, Eddeland A. Anomalous distal branching of the median nerve. Scan J Plast Reconstr Surg 1971;5:149-52.

3. Winkelman NZ, Spinner M. A variant high sensory branch of the median nerve to the third web space. Bull Hosp Joint Dis 1973;34: $161-6$.

4. Lacoste P, Dalle M. Anomalie arterielle de l'avant-bras et de la main. Essai d'interpretation embryologique. Comptes Rendus de Association des Anatomistes 1966;132:563-70.

5. Lanz U. Anatomical variations of the median nerve in the carpal tunnel. J Hand Surg Am 1977;2:44-53.

6. Chalmers J. Unusual causes of peripheral nerve compression. Hand 1978;10:168-75.

7. Kornberg M, Aulicino PL, DuPuy TE. Bifid median nerve with three thenar branches - case report. J Hand Surg Am 1983;8:583-4.

8. Fernandez-Garcia S, Pi-Folguera J, Estallo-Marino F. Bifid median nerve compression due to a musculotendinous anomaly of FDS to the middle finger. J Hand Surg Am 1994;19B:616-7.

9. Sundaram S, Kumar M, Sethupathy B, Nayak S, Krishnamurthy A. Split median nerve with variation in its common digital branch - a case report. Neuroanatomy 2008;7:15-6.

10. Natsis K, Karanassos MT, Papathanasiou E, Noussios G. A coexisting anatomical variation of median and ulnar nerves in a cadaver palm. Folia Morphol (Warsz) 2012;71:269-74.

11. Natsis K, Paraskevas G, Piagkou M. An unusual origin and course of multiple branches of the median nerve to the thenar muscles: a case report. Aristotle University Medical Journal 2013;40:41-4.

12. Barbe M, Bradfield J, Donathan M, Elmaleh J. Coexistence of multiple anomalies in the carpal tunnel. Clin Anat 2005;18:251-9.

13. Natsis K, Lordache G, Gigis I, Kyriazidou A., Lazaridis N, Noussios G, Paraskevas G. Persistent median artery in the carpal tunnel: anatomy, embryology, clinical significance, and review of the literature. Folia Morphol (Warsz) 2009;68:193-200.

14. Sañudo JR, Chikwe J, Evans SE. Anomalous median nerve associated with persistent median artery. J Anat 1994;185(Pt 2):447-51.

15. Schultz RJ, Endler PM, Huddleston HD. Anomalous median nerve and an anomalous muscle belly of the first lumbrical associated with carpal-tunnel syndrome. J Bone Joint Surg Am 1973;55:1744-6.

16. Engineer NJ, Hazani R, Mowlavi A, Neumeister MW, Lee WP, Wilhelmi BJ. Variations in the anatomy of the third common digital nerve and landmarks to avoid injury to the third common digital nerve with carpal tunnel release. Eplasty 2008;8:e51.

17. Agarwal P, Gupta S, Yadav P, Sharma D. Cadaveric study of anatomical variations of the median nerve and persistent median artery at wrist. Indian J Plast Surg 2014;47:95-101. 
18. Palmer AK, Toivonen DA. Complications of endoscopic and open carpal tunnel release. J Hand Surg Am 1999;24:561-5.

19. Takami H, Takahashi S, Ando M. Bipartite median nerve with a double compartment within the transverse carpal canal. Arch Orthop Trauma Surg 2001;121:230-1.

20. Bayrak IK, Bayrak AO, Kale M, Turker H, Diren B. Bifid median nerve in patients with carpal tunnel syndrome. J Ultrasound Med 2008;27:1129-36.

21. Cavallo A V, Slattery PG, Barton RJ. Endoscopic carpal tunnel release and congenital anomalies of the median nerve. Hand Surg 2003;8: $265-70$.

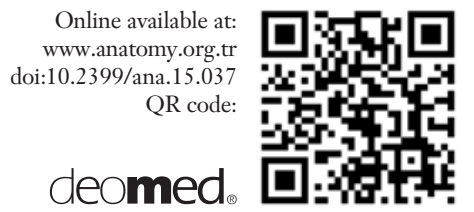

22. Pierre-Jerome C, Smitson RD, Shah RK, Moncayo V, Abdelnoor M, Terk MR. MRI of the median nerve and median artery in the carpal tunnel: prevalence of their anatomical variations and clinical significance. Surg Radiol Anat 2010;32:315-22.

23. Duymus M, Yilmaz O, Ulasli AM, Asal N, Kosar U. Coexistence of trifid and bifid median nerve in a patient with bilateral carpal tunnel syndrome. Turk Neurosurg 2013;23:685-7.

24. Kasius KM, Claes F, Meulstee J, Verhagen WI. Bifid median nerve in carpal tunnel syndrome: do we need to know? Muscle Nerve 2014; 50:835-43.

Correspondence to: Konstantinos Natsis MD, PhD

Laboratory of Anatomy, School of Medicine,

Faculty of Health Sciences, Aristotle University,

Thessaloniki, Macedonia, Greece

e-mail: natsis@auth.gr

Conflict of interest statement: No conflicts declared.

This is an open access article distributed under the terms of the Creative Commons Attribution-NonCommercial-NoDerivs 3.0 Unported (CC BY-NCND3.0) Licence (http://creativecommons.org/licenses/by-nc-nd/3.0/) which permits unrestricted noncommercial use, distribution, and reproduction in any medium, provided the original work is properly cited. Please cite this article as: Natsis K. High origin of the third digital branch of the median nerve. Anatomy 2016;10(1):71-74. 